\title{
Identifying potential geothermal reservoirs in Denmark
}

\author{
Anders Mathiesen, Lars Henrik Nielsen and Torben Bidstrup
}

Concerns about climate change have led to increased interest in geothermal energy as one way of reducing the consumption of fossil fuels and thus limit $\mathrm{CO}_{2}$ emissions. Use of geothermal energy is based on well-established technologies, a high degree of security of supply, and little visual or noise inconvenience. More than one hundred plants have been established in Europe.

There is a large potential for using geothermal energy from the Danish subsurface, as first pointed out by Balling (1976). Geothermal energy is highly suitable for district heating systems and is expected to cover a large part of the demand for district heating in the future. Two Danish geothermal plants, the Thisted plant in northern Jylland and the Margretheholm demonstration plant near Copenhagen (Fig. 1), have shown that it is possible to produce large amounts of warm water for district heating. Only $5-10 \%$ of the total energy output from the plant is used to extract the heat from the subsurface by pumping warm forma-

Fig. 1. The distribution of potential sandstone reservoirs in Denmark with depths in the 800-3000 $\mathrm{m}$ interval and thicknesses above $25 \mathrm{~m}$. Dark grey and black areas indicate where the reservoirs are too deep (Gassum in northern Jylland; Bunter in western Jylland - both located in the central parts of the Danish Basin). Light grey areas indicate where reservoirs are absent (Ringkøbing-Fyn High) or too shallow (less than $c .800 \mathrm{~m}$; northernmost Jylland). Hatched areas indicate two or more reservoirs with geothermal potential. Green areas: not mapped. tion water to the surface and returning it to the subsurface in a closed system. The plants use absorption warmth pumps, which need steam and hence give rise to consumption of (fossil) fuel. Both Danish plants have two wells, a production well and an injection well in which the cooled formation water is returned to the geological reservoir at about $1 \mathrm{~km}$ away from the production point, in order to avoid mixing of warm and cold water (Fig. 2). Geothermal energy can also be used for electricity production, but Danish subsurface temperatures are currently not believed to be sufficiently high to produce electricity directly.

Because geothermal energy is expected to play an increasingly important role in the energy strategy of Denmark, the

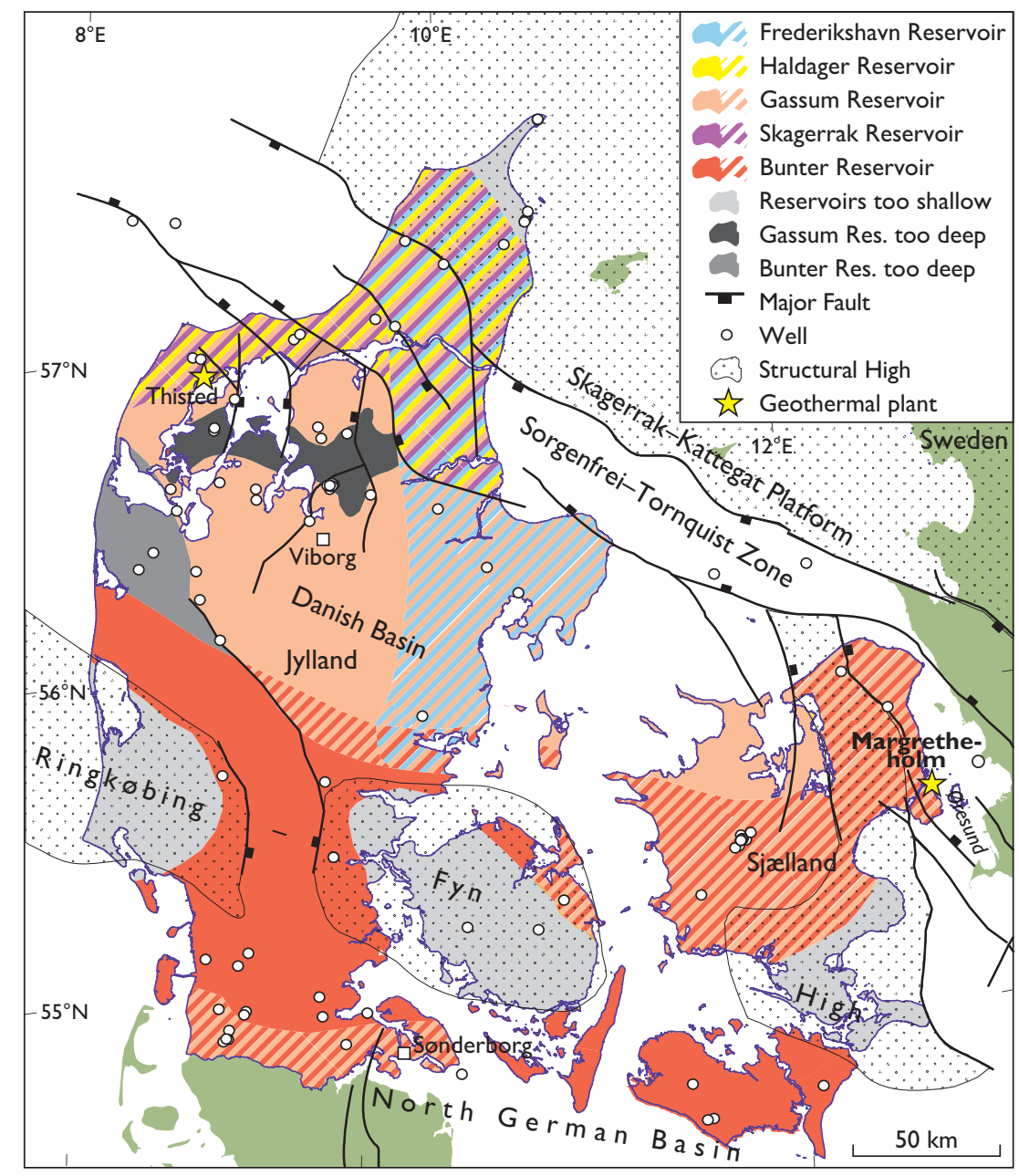




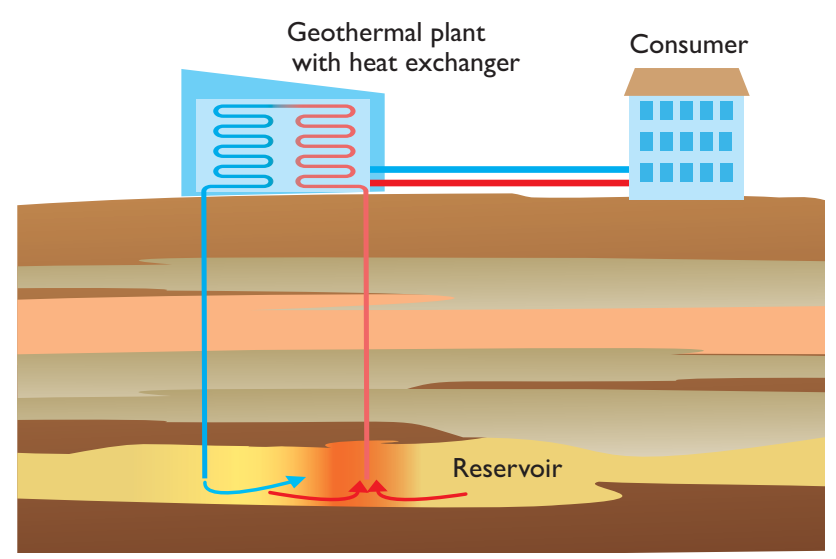

Fig. 2. Schematic diagram illustrating the geothermal concept used in Denmark. In the geothermal plant a production well pumps up warm water (red line) from the underground reservoir, and an injection well (blue line) returns the cooled water to the reservoir.

Geological Survey of Denmark and Greenland (GEUS) and the Danish Energy Agency have conducted a regional study to update the assessment of the geothermal potential in Denmark (Mathiesen et al. 2009). Based on existing well, seismic and temperature data and the detailed knowledge of the subsurface stratigraphy gathered by GEUS over many years, the assessment has documented a huge geothermal potential in many parts of Denmark. The focus of the study was to evaluate (1) the potential of geothermal energy in Denmark and (2) if it can contribute significantly to the Danish strategy for a safe, sustainable and reliable supply of energy. The specific potential in local areas was not evaluated in detail; however, a well-defined and stepwise procedure to develop local geothermal prospects by integrating existing and new data is suggested.

\section{Potential reservoirs and areas of interest}

The Danish subsurface can be divided into five major structural parts: the North German Basin, the Ringkøbing-Fyn High, the Danish Basin, the Sorgenfrei-Tornquist Zone and the Skagerrak-Kattegat Platform (Fig. 1). These structural divisions exert a decisive influence on the geothermal prospectivity of the Danish subsurface, as they essentially determine the distribution, thicknesses, facies types and burial depths of the potential reservoirs (Nielsen 2003; Nielsen et al. 2004). The $1-10 \mathrm{~km}$ thick Mesozoic succession has been the target for hydrocarbon exploration since 1935 and is thus relatively well known from about 60 deep wells and seismic data acquired over many years, although with a highly variable data coverage and quality. The data show that the most promising geothermal reservoirs occur within the Triassic - Lower Cretaceous succession in the Danish Basin and the North German Basin, separated by the Ringkøbing-Fyn High which shows a lower potential. Based on regional geological studies, four main stratigraphical units with a regional geothermal potential have been identified (Nielsen et al. 2004). Within these four main units, we have defined five geothermal reservoirs on the basis of their stratigraphical and spatial extent. Each reservoir comprises a large number of sandstone layers that are potential aquifers. The new assessment shows that large areas in both basins have a good geothermal potential, as they contain several porous, water-bearing sandstone reservoirs in the economic interval 800-3000 $\mathrm{m}$ below the surface with formation temperatures of $25-90^{\circ} \mathrm{C}$ (Mathiesen et al. 2009).

The principal challenge for successful geothermal exploration is to assess whether good reservoir properties are present in terms of sufficient layer thickness, porosity, permeability, temperature and formation water geochemistry. These geological factors are used to evaluate whether the thermal energy of the formation water can be exploited economically and used for heating purposes. By combining knowledge of the geographical distribution of the stratigraphical units with the potential reservoirs, their mapped burial depths and estimates of where the cumulative thickness of the reservoir sandstones exceeds c. $25 \mathrm{~m}$ at depths of $800-3000 \mathrm{~m}$, a useful indication of the regional geothermal potential is provided.

Temperature and salinity of the formation water in the potential reservoirs increase with increasing depth. Based on data from a number of wells a general temperature-depth relation has been established, showing a gradient of $25-30^{\circ} \mathrm{C} / \mathrm{km}$. The salinity of the formation water shows a general increase of about $10 \% / \mathrm{km}$ burial depth, but large variations are found. Porosity and permeability decrease with increasing depth due to mechanical compaction and formation of diagenetic minerals that reduce the pore volume (porosity) and the connections between the pores (permeability). Several of these properties are directly related to the petrography of the sediment source areas and the grain size distribution of the material supplied to the basins. Thus the various depositional processes during the formation of the reservoirs and their subsequent burial depths determine their qualities as geothermal reservoirs. However, the mutual dependency of the various factors and processes is not fully understood, which weakens the predictive strength and reliability of the geological models currently in use to identify areas of interest.

Figure 1 shows regions where sandstone-rich reservoirs are expected to have geothermal potential by combining geographical distribution and burial depth information of the five reservoirs. The map also indicates where further detailed research and investigations are required if geothermal ener- 
gy production is to be further developed (Mathiesen et al. 2009). The central part of the Danish Basin is promising, whereas the potential of areas located around the $800 \mathrm{~m}$ and $3000 \mathrm{~m}$ cut-off limits is highly uncertain. Areas located along the Ringkøbing-Fyn High are considered less prospective.

\section{The need for further development}

Interest in the use of geothermal energy has increased over the past five years. So far, the Thisted and Margretheholm plants are the only working geothermal plants in Denmark. However, GEUS has carried out evaluations of the geothermal potential in several local areas in Denmark with positive conclusions. It is expected that new Danish geothermal plants will be established in Sønderborg and Viborg within the next few years. The existing Thisted plant has produced heat from the Gassum Formation (the Gassum reservoir) for almost 20 years without notable production or injection problems, and the newly established Margretheholm plant produces heat from the Bunter Sandstone Formation (the Bunter reservoir).

During planning of the Margretheholm plant new seismic data were acquired in 2001, and GEUS carried out a geological evaluation of the geothermal potential. The study used old and new seismic data to map the distribution, the tops and the lateral variations of the reservoirs, as well as faults. Faults may reduce the lateral continuity of a reservoir (Fig. 3). From this study it was concluded that the Bunter reservoir is found south of the Ringkøbing-Fyn High, on parts of the high and

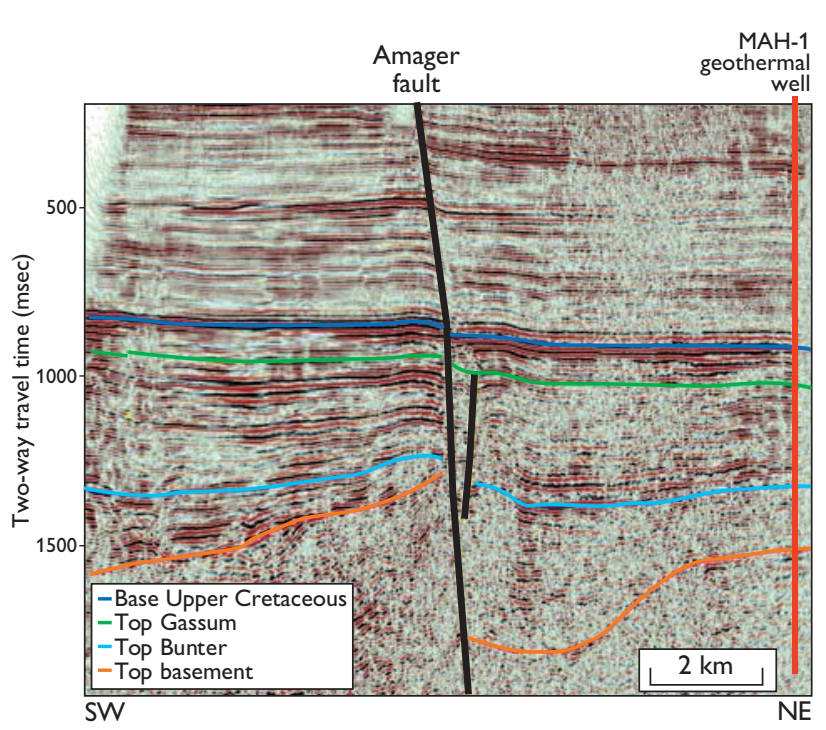

Fig. 3. SW-NE-trending seismic profile south-west from Margretheholm. The profile illustrates the importance of mapping faults, which can reduce the lateral reservoir continuity. For location see Fig. 4. in the Danish Basin, and grades into the Skagerrak reservoir towards the north-eastern basin margin (Fig. 2; Mathiesen $e t$ al. 2009). The Bunter reservoir is dominated by fine-grained sandstones that were deposited in arid continental environments with fluvial channels, aeolian dunes and with some marine influence. In southern Sweden, analyses of existing cuttings from old wells and data from new wells documented the presence of a loose, medium- to coarse-grained, quartzitic sandstone composed of sub-rounded quartz and feldspar grains without overgrowth of minerals or other signs of corrosion and cementation. Data from the Swedish wells combined with log correlation to Danish wells indicated the presence of a c. $50 \mathrm{~m}$ thick, loose, conglomeratic sandstone unit in the basal part of the Bunter reservoir, and this unit was predicted to show high porosity and low degree of cementation at Margretheholm.

In 2002 and 2003 the Margretheholm-1 and -2 wells were drilled to about $2700 \mathrm{~m}$ depth and confirmed the presence of several sandstone-rich aquifers in both the Gassum and Bunter reservoirs. Studies of the new wells and results from log correlation with other wells in the Copenhagen region, Øresund and southern Sweden confirmed the previous geological model of the Bunter reservoir and strengthened the indications of a large geothermal potential in the Copenhagen area (Figs 3,4). No cores were taken from the new wells, but both wells encountered a promising aquifer in the Bunter reservoir with satisfying test results, and in 2006 the Mar-

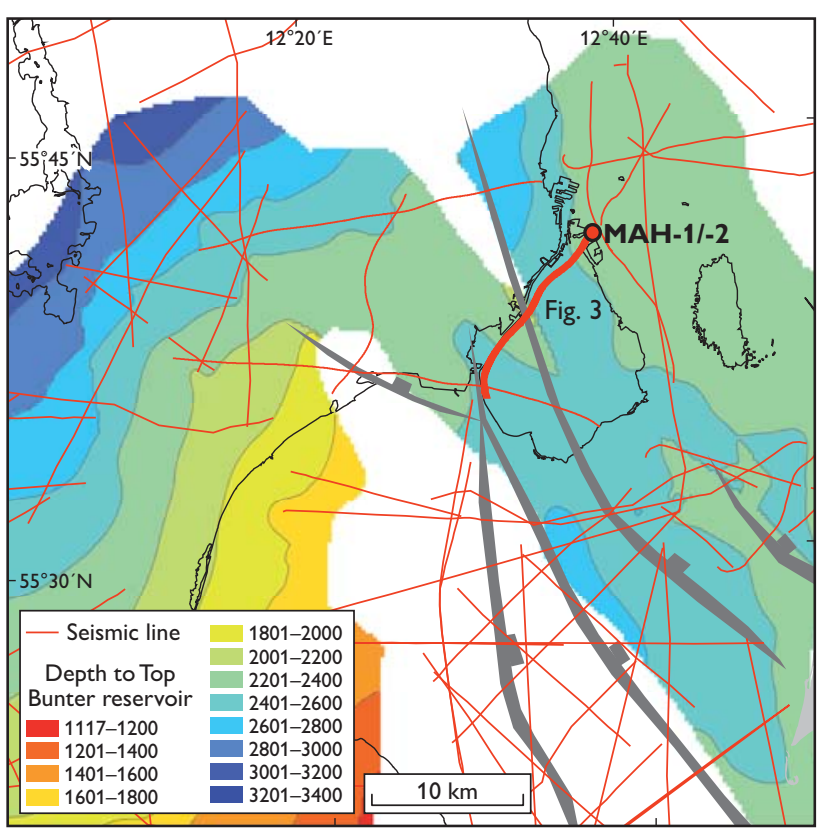

Fig. 4. Depth to the top of the Bunter reservoir, illustrating southwards shallowing of the reservoir top and its partition by faults (grey tone). Red dot: Margretheholm and the wells MAH-1 and MAH-2. 
gretheholm geothermal plant was opened based on water with a temperature of $73^{\circ} \mathrm{C}$.

Despite the encouraging results, a more detailed study of the new Margretheholm wells is required, including correlation with other wells in the Danish area and with the wellknown Bunter Sandstein in the German part of the North German Basin to be able to estimate the potential of other sandstone-rich layers in the Bunter reservoir, both in the Copenhagen area and in other places in the southern part of Denmark. Further studies are needed because it has been decided that the Copenhagen area should be $\mathrm{CO}_{2}$-neutral by 2025. To achieve this goal, the Margretheholm plant is expected to play a major role in the use of geothermal energy for district heating. This will require an expansion of the plant over the next five years. Therefore a more detailed evaluation is necessary, both to minimise the prospected risk and to enhance the optimal use of the subsurface below Copenhagen for geothermal energy.

\section{Future potential - towards a new resource assessment}

A more environmentally friendly Denmark has to include geothermal energy as a significant part of the energy supply. It is estimated that the geothermal resources in Denmark can last several hundred years with the present heat consumption, and only a small fraction of this potential is utilised by the two existing geothermal power plants (Mathiesen et al. 2009).

A major challenge within geothermal prospecting is to find suitable and sustainable reservoirs (small number of faults and lateral facies changes) and sufficient flow capacity (thickness, porosity and permeability) of warm water. Permeability is critical but difficult to predict since large variations occur depending on the depositional facies, provenance, mineralogical composition, burial history and position in the basin. One of the barriers for a significant increase in the exploitation of the large geothermal resources in Denmark is the geological uncertainty in the exploration phase. This uncertainty is related to the possibility of making accurate and reliable predictions about the presence of high-quality reservoirs with high lateral continuity below the urban areas, where infrastructure and consumers are located. Precise predictions depend not only on existing well and seismic data, which vary highly in density and quality, but also on our understanding of the geological processes that led to the formation of the geothermal reservoirs.

A large, newly funded, multi-disciplinary research project carried out jointly by GEUS, the University of Aarhus, the Geological Survey of Sweden, Deutsches GeoForschungsZentrum and DONG Energy aims to assess these challenges in detail in order to encourage the utilisation of geothermal energy by investigating the critical elements in the exploitation of the geothermal resources and integrating the results on a GIS platform. The project will use existing and new geological and geophysical data and methods. By conducting detailed studies of relevant, sandstone-rich reservoirs and the diagenetic processes that affected the reservoirs since deposition, the project will provide new data leading to improved understanding of the spatial variations in the physical characteristics and quality of the reservoirs. New seismic data will be acquired, and interpretations of these data and old data will increase our knowledge about lateral reservoir variations and will form the basis of a new consistent 3-D subsurface temperature model.

Thermal and fluid flow modelling using various schemes of combined production and re-injection wells can provide more detailed information on the thermal resources that can be extracted from the reservoirs and their thermal life-time, and it will be possible to quantify the additional amount of heat that can be extracted from less prospective layers both within and adjacent to the geothermal reservoirs. Traditionally this is not included in estimates of resources, but it will provide higher and more realistic values.

\section{References}

Balling, N. 1976: Geothermal models of the crust and uppermost mantle of the Fennoscandian Shield in South Norway and the Danish Embayment. Journal of Geophysics 42, 237-256.

Mathiesen, A., Kristensen, K., Bidstrup, T. \& Nielsen, L.H. 2009: Vurdering af det geotermiske potentiale i Danmark. Danmarks og Grønlands Geologiske Undersøgelse Rapport 2009/59, 30 pp.

Nielsen, L.H. 2003: Late Triassic - Jurassic development of the Danish Basin and the Fennoscandian Border Zone, southern Scandinavia. In: Ineson, J.R. \& Surlyk, F. (eds): The Jurassic of Denmark and Greenland. Geological Survey of Denmark and Greenland Bulletin 1, 459-526.

Nielsen, L.H., Mathiesen, A. \& Bidstrup, T. 2004: Geothermal energy in Denmark. Geological Survey of Denmark and Greenland Bulletin 4, 17-20. 